\author{
Karim Asehnoune \\ Pierre Joachim Mahe \\ Philippe Seguin \\ Samir Jaber \\ Boris Jung \\ Christophe Guitton \\ Nolwen Chatel-Josse \\ Aurelie Subileau \\ Anne Charlotte Tellier \\ Françoise Masson \\ Benoit Renard \\ Yannick Malledant \\ Corinne Lejus \\ Christelle Volteau \\ Véronique Sébille \\ Antoine Roquilly
}

Received: 10 February 2012

Accepted: 30 May 2012

Published online: 10 July 2012

(C) Copyright jointly held by Springer and ESICM 2012

Electronic supplementary material

The online version of this article (doi:10.1007/s00134-012-2619-8) contains supplementary material, which is available to authorized users.

K. Asehnoune - P. J. Mahe .

N. Chatel-Josse - C. Lejus · A. Roquilly Intensive Care Unit, Anaesthesia and Critical Care Department, Hôtel Dieu-HME, University Hospital of Nantes, Nantes, France

\section{A. Roquilly}

e-mail: antoine.roquilly@ chu-nantes.fr

P. Seguin - Y. Malledant Intensive Care Unit, Anaesthesia and Critical Care Department, University Hospital of Rennes, Rennes, France

S. Jaber - B. Jung

Intensive Care Unit, Anaesthesia and Critical Care Department, Saint Eloi University Hospital of Montpellier, Montpellier, France

\section{Guitton}

Medical Intensive Care Unit, University Hospital of Nantes, Nantes, France

\title{
Etomidate increases susceptibility to pneumonia in trauma patients
}

A. Subileau

Intensive Care Unit, Anaesthesia and Critical Care Department, University Hospital of Brest, Brest, France

\section{A. C. Tellier}

Intensive Care Unit, Anaesthesia and Critical Care Department, University Hospital of Tours, Tours, France

\section{F. Masson}

Intensive Care Unit, Anaesthesia and Critical Care Department, University Hospital of Bordeaux, Bordeaux, France

\section{B. Renard}

Intensive Care Unit, Hospital of La Roche Sur Yon, La Roche Sur Yon, France

C. Volteau - V. Sébille

Cellule de Biostatistique, EA 4275,

UFR de Pharmacie, University of Nantes, Nantes, France

\section{K. Asehnoune (-)}

Service d'anesthésie réanimation,

CHU de Nantes, 1 place Alexis Ricordeau, 44093 Nantes Cedex 1, France

e-mail: karim.asehnoune@chu-nantes.fr

Tel.: +33-2-40083005

Fax: +33-4-40087382
Abstract Purpose: To investigate the impact of etomidate on the rate of hospital-acquired pneumonia (HAP) in trauma patients and the effects of hydrocortisone in etomidate-treated patients. Methods: This was a sub- study of the HYPOLYTE

multi-centre, randomized, doubleblind, placebo-controlled trial of hydrocortisone in trauma patients (NCT00563303). Inclusion criterion was trauma patient with mechanical ventilation $(\mathrm{MV})$ of $\geq 48 \mathrm{~h}$. The use of etomidate was prospectively collected. Endpoints were the results of the cosyntropin test and rate of HAP on day 28 of follow-up. Results: Of the 149 patients enrolled in the study, 95 (64\%) received etomidate within $36 \mathrm{~h}$ prior to inclusion. $79(83 \%)$ of 95 patients receiving etomidate and 34 of the $54(63 \%)$ not receiving etomidate had corticosteroid insufficiency $(p=0.006)$. The

administration of etomidate did not alter basal cortisolemia $(p=0.73)$, but it did decrease the delta of cortisolemia at $60 \mathrm{~min}(p=0.007)$. There was a correlation between time from etomidate injection to inclusion in the study and sensitivity to corticotropin $\left(R^{2}=0.19\right.$; $p=0.001)$. Forty-nine $(51.6 \%)$ patients with etomidate and 16 (29.6\%) patients without etomidate developed HAP by day 28 $(p=0.009)$. Etomidate was associated with HAP on day 28 in the multivariate analysis (hazard ratio 2.48; $95 \%$ confidence interval 1.19-5.18; $p=0.016$ ). Duration of MV with or without etomidate was 
not significantly different $(p=0.278)$. Among etomidateexposed patients, $18(40 \%)$ treated with hydrocortisone developed HAP compared with $31(62 \%)$ treated with placebo $(p=0.032)$. Etomidate-exposed patients treated with hydrocortisone had fewer ventilator days $(p<0.001)$.
Conclusions: Among the patients enrolled in the study, etomidate did not alter basal cortisolemia, but it did decrease reactivity to corticotropin. We suggest that in trauma patients, etomidate is an independent risk factor for HAP and that the administration of hydrocortisone should be considered after etomidate use.

Keywords Etomidate .

Adrenal insufficiency .

Bacterial pneumonia - Trauma .

Hydrocortisone

\section{Introduction}

Etomidate has a favourable haemodynamic profile and is frequently used as a single bolus for rapid sequence intubation $[1,2]$. However, the use of etomidate remains controversial in critically ill patients [3]. Etomidate inhibits $11 \beta$-hydroxylase and induces transient corticosteroid insufficiency [4]. Authors of clinical trials have frequently reported an increased rate of adrenal insufficiency and an increased risk of death with etomidate use $[5,6]$. In a study involving a general population of intensive care unit (ICU) patients, etomidate did not alter specific outcomes (organ failures, duration of mechanical ventilation) or mortality compared with ketamine [7]. In a recently published systematic review, the authors confirmed an increased mortality rate with the use of etomidate in a sub-group of patients with sepsis [8]. However, hydrocortisone treatment after etomidate use did not reduce the mortality of septic patients [9] and did not reduce organ failures in critically ill patients [10].

Trauma patients are highly susceptible to nosocomial infection [11], and the impact of etomidate is poorly studied in this population. It has been demonstrated that up to $70 \%$ of trauma patients developed a critical illness-related corticosteroid insufficiency (CIRCI) [12-14] and that this could increase the risk of hospital-acquired pneumonia (HAP) $[15,16]$. We have recently demonstrated that lowdose hydrocortisone decreases the rate of HAP in multiple trauma patients with CIRCI [17]. Etomidate may increase the rate of post-traumatic complications, but little data are available to date on this specific population of patients [18]. To the best of our knowledge, the ability of hydrocortisone to overcome the effects of etomidate has not yet been delineated in trauma patients.

For the study reported here, we used data from the HYPOLYTE trial, a prospective multi-centre study of lowdose hydrocortisone treatment in intubated trauma patients [17]. We hypothesized that a single dose of etomidate increases the proportion of CIRCI and the rate of HAP. We also tested the effects of the hydrocortisone treatment on the proportion of HAP in patients receiving etomidate.

\section{Materials and methods}

Study design

This study is a sub-study of the HYPOLYTE trial, a multi-centre, randomized, double-blind, placebo-controlled trial of hydrocortisone in severe trauma patients [17]. Following approval by the Institutional Review Board of Angers (France), patients in seven French ICUs were enrolled in the HYPOLYTE trial from 15 November 2006 to 4 August 2009. Prior to enrollment, written informed consent was obtained from a next-of-kin. Retrospective consent, if possible, was obtained from patients.

\section{Patients}

All of the 149 patients randomized in the HYPOLYTE trial were included in the analysis for this sub-study. In the HYPOLYTE trial, the inclusion criteria were multiple trauma, age of $>15$ years 3 months and the expectation that mechanical ventilation would be required for $>48 \mathrm{~h}$. Exclusion criteria were previous adrenal insufficiency, previous immunosuppression (See [17] for definitions), treatment with corticosteroids within the last 6 months and pregnancy. Etomidate use was not controlled for in the study.

\section{Hydrocortisone therapy}

For the purpose of the HYPOLYTE trial, treatment with hydrocortisone or placebo were started in the first $36 \mathrm{~h}$ following the trauma. Hydrocortisone (Upjohn Serb ${ }^{\circledR}$, Paris, France) or placebo were administered for 7 days in patients with CIRCI (continuous intravenous infusion, $200 \mathrm{mg} / \mathrm{day}$ for 5 days, $100 \mathrm{mg}$ on day 6 and $50 \mathrm{mg}$ on day 7) and were stopped during the first 2 days that patients were CIRCI-free (after the results of the corticotropin test had been received). 
Critical illness-related corticosteroid insufficiency definition

Immediately before beginning the treatment, but at least $8 \mathrm{~h}$ after a bolus injection of etomidate, a short corticotropin test was performed in all 149 patients. Cortisolemia was assessed before and 30 and $60 \mathrm{~min}$ after an intravenous bolus of $0.25 \mathrm{mg}$ of corticotropin (Novartis, RueilMalmaison, France). The delta of cortisolemia was calculated as [cortisolemia (30 or $60 \mathrm{~min}$ as stated) basal cortisolemia]. CIRCI was defined as a basal cortisolemia level of $<15 \mu \mathrm{g} / \mathrm{dL}(413 \mathrm{nmol} / \mathrm{L})$ or a delta of cortisolemia of $<9 \mu \mathrm{g} / \mathrm{dL}(248 \mathrm{nmol} / \mathrm{L})$.

\section{Hospital-acquired pneumonia definition [19]}

Pneumonia was considered as diagnosis when at least two signs (body temperature $>38{ }^{\circ} \mathrm{C}$; leukocytosis $>12,000 / \mathrm{mL}$ or leukopenia $<4,000 / \mathrm{mL}$; purulent pulmonary secretions) were associated with the appearance of a new infiltrate or changes in an existing infiltrate on the chest X-ray. Diagnosis was confirmed by tests on a respiratory tract sample using a quantitative culture with a predefined positive threshold of $10^{4}$ colony-forming units per milliliter (CFU/ $\mathrm{mL}$ ) for a bronchoalveolar lavage or nonbronchoscopic sample or $10^{3} \mathrm{CFU} / \mathrm{mL}$ for a protected specimen brush. HAP was defined as pneumonia that occurred $48 \mathrm{~h}$ after admission that had not been incubating at the time of admission.

\section{Data collection}

Overall patient characteristics, including demographics, injury severity score and abbreviated injury score, fluid infusions, vasopressors, antibiotic prophylaxis, etomidate use, surgery, infections, organ failures, length of ventilatory support, ICU hospitalization and death on day 28 of follow-up were recorded.

\section{Endpoints}

The primary endpoint of the HYPOLYTE trial was HAP on day 28 of follow-up [17]. In this sub-study, the primary endpoint was the 28-day HAP rate and whether etomidate increased the HAP rate. We compared patients with or without etomidate therapy. Secondary outcomes were the results of the short corticotropin test, duration of mechanical ventilation (MV) and ICU length of stay and mortality.

\section{Statistical analysis}

Continuous variables are expressed as the median and interquartile range (IQR) and categorical variables as percentage. Characteristics and outcomes of patients with etomidate and those without etomidate were compared with the $\chi^{2}$ test, Student's $t$ test or the Wilcoxon rank-sum test were used as appropriate. Multivariate analyses of the occurrence of HAP on day 28 were carried out using logistic regression models adjusted on hydrocortisone therapy. The calibration of the models was tested by the Hosmel-Lemeshow's test. The effect of etomidate on HAP within 28 days was assessed in the hydrocortisone and placebo groups by means of a Cox multivariate proportional hazards model that included three predefined covariates: centre, traumatic brain injury (TBI, presence or absence), and the injury severity score $(\leq 30$ or $>30)$. Corresponding hazard ratios (HR) along with their $95 \%$ confidence intervals (CI) were reported. A sensitivity analysis was performed using propensity score-adjusted models. The propensity score was constructed using logistic regression analyses for etomidate use, including variables recorded before the induction of anaesthesia, such as age, sex, Injury Severity Score (ISS), TBI and hypotension. The caliper matching method was used for matching $54(100 \%)$ of the patients in the non-etomidate group with 54 patients in the etomidate group (caliper size: one-quarter of the standard deviation of the logit of the propensity score). Discrimination of the propensity-adjusted logistic regression model was assessed using the area under the receiver-operating characteristic curve ( $c$ statistic). All statistical tests were two-sided. A $p$ value of $<0.05$ was considered to be statistically significant. Statistical analyses were performed using the SAS ver. 9.1 (SAS, Cary, NC) software package.

\section{Results}

Patients

Of the 149 patients analysed, $95(64 \%)$ received a single bolus of etomidate prior to inclusion in the study [see Electronic Supplementary Material (ESM) Fig. S1 for flow chart]. No patient received etomidate after study inclusion. There were no differences in the general characteristics of patients who received etomidate (etomidate group) compared with those who had not received etomidate (non-etomidate group) except for the time from trauma to tracheal intubation [60 (IQR 30-120) min and 105 (IQR 30-270) min, respectively; $p=0.014$ ) (Table 1). The median time from induction of anaesthesia to corticotropin test was 22 (IQR 20-28) $\mathrm{h}$ in the nonetomidate group and 22 (IQR 17-29) $\mathrm{h}$ in the etomidate group $(p=0.826)$.

Etomidate effects on basal cortisolemia and results of the corticotropin test

Of the 95 patients in the etomidate group and 54 patients in the non-etomidate group, $79(83 \%)$ and $34(63 \%)$, 
Table 1 General characteristics of the patients

\begin{tabular}{|c|c|c|c|}
\hline Characteristics & No etomidate $(N=54)$ & Etomidate $(N=95)$ & $p$ value $^{\mathrm{a}}$ \\
\hline Age (years), mean (SD) & $36(17)$ & $36(18)$ & 0.902 \\
\hline Men, $N(\%)$ & $47(87)$ & $70(73.7)$ & 0.056 \\
\hline \multicolumn{4}{|l|}{ Medical history, $N(\%)$} \\
\hline Diabetes mellitus & $1(1.85)$ & $4(4.2)$ & 0.653 \\
\hline Cardiac insufficiency & $1(1.85)$ & $4(4.2)$ & 0.653 \\
\hline Obesity & $6(11)$ & $15(15.8)$ & 0.430 \\
\hline Chronic pulmonary disease & $1(1.9)$ & $4(4.2)$ & 0.653 \\
\hline Smoking & $2(3.7)$ & $3(3.2)$ & 1 \\
\hline Traumatic brain injury, $N(\%)$ & $29(53.7)$ & $55(57.9)$ & 0.620 \\
\hline Injury severity score, median (IQR) & $26(22-35)$ & $30(22-36)$ & 0.217 \\
\hline \multicolumn{4}{|l|}{ AIS, median (IQR) } \\
\hline Brain/neck & $3(0-4)$ & $3(1-4)$ & 0.406 \\
\hline Face & $0(0-2)$ & $1(0-2)$ & 0.406 \\
\hline Thorax & $3(2-3)$ & $3(2-3)$ & 0.411 \\
\hline Abdomen/perineum & $2(0-3)$ & $2(0-3)$ & 0.154 \\
\hline Extremities/pelvis & $2(1-3)$ & $2(0-3)$ & 0.987 \\
\hline Skin & $0(0-1)$ & $0(0-1)$ & 0.481 \\
\hline Aspiration pneumonia, $N(\%)$ & $1(1.9)$ & $3(3.2)$ & 1 \\
\hline Hypotension prior to inclusion, $N(\%)$ & $28(52.8)$ & $60(63.8)$ & 0.191 \\
\hline \multicolumn{4}{|l|}{ Fluid infusion prior to inclusion, median (IQR) } \\
\hline Red cell units $(N)$ & $4(0-7)$ & $4(0-10)$ & 0.21 \\
\hline Colloid fluid infusion (L) & $1(1-2.5)$ & $1(1-3)$ & 0.309 \\
\hline Crystalloid fluid infusion (L) & $3(2-4)$ & $2.5(1.5-4)$ & 0.466 \\
\hline Norepinephrine prior to inclusion, $\mu \mathrm{g} / \mathrm{kg}$ per min, median (IQR) & $0.26(0.13-0.48)$ & $0.30(0.15-0.50)$ & 0.671 \\
\hline Duration of initial surgical procedure, h, median (IQR) & $2(2-4)$ & $2(1-5)$ & 0.463 \\
\hline \multicolumn{4}{|l|}{ Time from trauma to tracheal intubation } \\
\hline Median, min (IQR) & $105(30-270)$ & $60(30-120)$ & 0.014 \\
\hline Time from Induction of anaesthesia to cosyntropin test, min, median (IQR) & $1340(1,170-1,670)$ & $1,345(992-1,710)$ & 0.826 \\
\hline Time from trauma to hydrocortisone therapy, min, median (IQR) & $1,541(1,260-1,800)$ & $1425(1,080-1,778)$ & 0.137 \\
\hline Hospital-acquired pneumonia, $N(\%)$ & $16(29.6)$ & $49(51.6)$ & 0.009 \\
\hline
\end{tabular}

AIS Abbreviated injury scale; a global severity scoring system that classifies each injury according to its relative severity on a 6-point ordinal scale: 1 minor, 2 moderate, 3 serious, 4 severe, 5 critical, 6 maximal (or untreatable), $I Q R$ interquartile range, $S D$ standard deviation

respectively, satisfied the criteria for CIRCI $(p=0.006)$. Basal cortisolemia was not different between the etomidate group and the non-etomidate group [20.0 (IQR 12.5-27.9) and 18.5 (IQR 13.4-25.4) $\mu \mathrm{g} / \mathrm{dL}$, respectively; $p=0.73]$. The delta of cortisolemia at $60 \mathrm{~min}$ was significantly lower in the etomidate group than in the nonetomidate group [7.6 (IQR 2.7-14.0) and 12.9 (IQR 5.2-19.0) $\mu \mathrm{g} / \mathrm{dL}$, respectively; $p=0.007]$ (Table 2). Time from induction of anaesthesia to corticotropin test was not correlated with basal cortisolemia in the etomidate or the non-etomidate group (Fig. 1a, b). Time from induction of anaesthesia to the cosyntropin test was correlated with delta cortisolemia in the etomidate group $\left(R^{2}=0.19, p=0.001\right.$; Fig. $\left.1 \mathrm{c}\right)$ but not in the nonetomidate group (Fig. 1d).

Etomidate was an independent risk factor for HAP

Sixteen $(29.6 \%)$ patients in the non-etomidate group and $49(51.6 \%)$ patients in the etomidate group
${ }^{a} p$ values are given for comparisons between etomidate and nonetomidate groups developed HAP by day $28(p=0.009)$. The median time to HAP was 4 (IQR 3-8) days in the non-etomidate group and 6 (IQR 4-8) days in the etomidate group ( $p=0.25$; see ESM Fig. S2 for Kaplan-Meier curves). We hypothesized that etomidate may be an independent risk factor for HAP and therefore performed a multivariate analysis for the risk factors of HAP. Twentynine variables potentially associated with the occurrence of HAP in trauma patients [19, 20] were tested by univariate analysis (Table 3 ). In the univariate analysis, HAP was associated (at $p<0.25$ ) with etomidate use, ISS, TBI and time from trauma to tracheal intubation (Table 3). After the logistic regression analysis, HAP remained associated with etomidate use [odds ratio (OR) $2.48,95 \%$ CI 1.19-5.18; $p=0.016]$ and TBI (OR 3.05, $95 \%$ CI $1.5-6.21 ; p=0.002$ ) (Table 4). In the sensitivity analysis, after adjustment for the propensity score and the study drug (hydrocortisone), the association between etomidate use and HAP remained significant (adjusted OR 2.52, $95 \%$ CI $1.08-5.87 ; p=0.032$ ) (Table 4). 
Table 2 Etomidate use alters adrenal function in trauma patients

\begin{tabular}{|c|c|c|c|}
\hline Adrenal function & No etomidate $(N=54)$ & Etomidate $(N=95)$ & $p$ value \\
\hline \multicolumn{4}{|l|}{ Corticotrophin test, $\mu \mathrm{g} / \mathrm{dL}$, median (IQR) } \\
\hline Basal cortisolemia & $18.5(13.4-25.4)$ & $20.0(12.5-27.9)$ & 0.73 \\
\hline Delta $^{\mathrm{a}} 30 \mathrm{~min}$ & $10.0(3.8-15.2)$ & $4.6(1.5-10.0)$ & $<0.001$ \\
\hline Delta $60 \mathrm{~min}$ & $12.9(5.2-19.0)$ & $7.6(2.7-14.0)$ & 0.007 \\
\hline \multicolumn{4}{|l|}{ CIRCI, $N(\%)$} \\
\hline Basal cortisolemia $\leq 15 \mu \mathrm{g} / \mathrm{dL}^{\mathrm{b}}$ & $16(30)$ & $34(36)$ & 0.44 \\
\hline Delta maximum $\leq 9 \mu \mathrm{g} / \mathrm{dL}^{\mathrm{b}}$ & $18(33)$ & $54(57)$ & 0.006 \\
\hline Basal $\leq 15$ and/or Delta maximum $\leq 9 \mu \mathrm{g} / \mathrm{dL}^{\mathrm{b}}$ & $34(63)$ & $79(83)$ & 0.006 \\
\hline Basal cortisolemia $\leq 10 \mu \mathrm{g} / \mathrm{dL}^{\mathrm{c}}$ & $9(17)$ & $14(15)$ & 0.754 \\
\hline Basal $\leq 10$ and/or Delta maximum $\leq 9 \mu \mathrm{g} / \mathrm{dL}^{\mathrm{c}}$ & $25(46)$ & $64(67)$ & 0.012 \\
\hline
\end{tabular}

CIRCI Critical illness-related corticosteroid insufficiency

${ }^{\text {a }}$ Delta $=$ Cortisolemia (30 or 60 min as stated): basal cortisolemia

b CIRCI definition from the HYPOLYTE trial
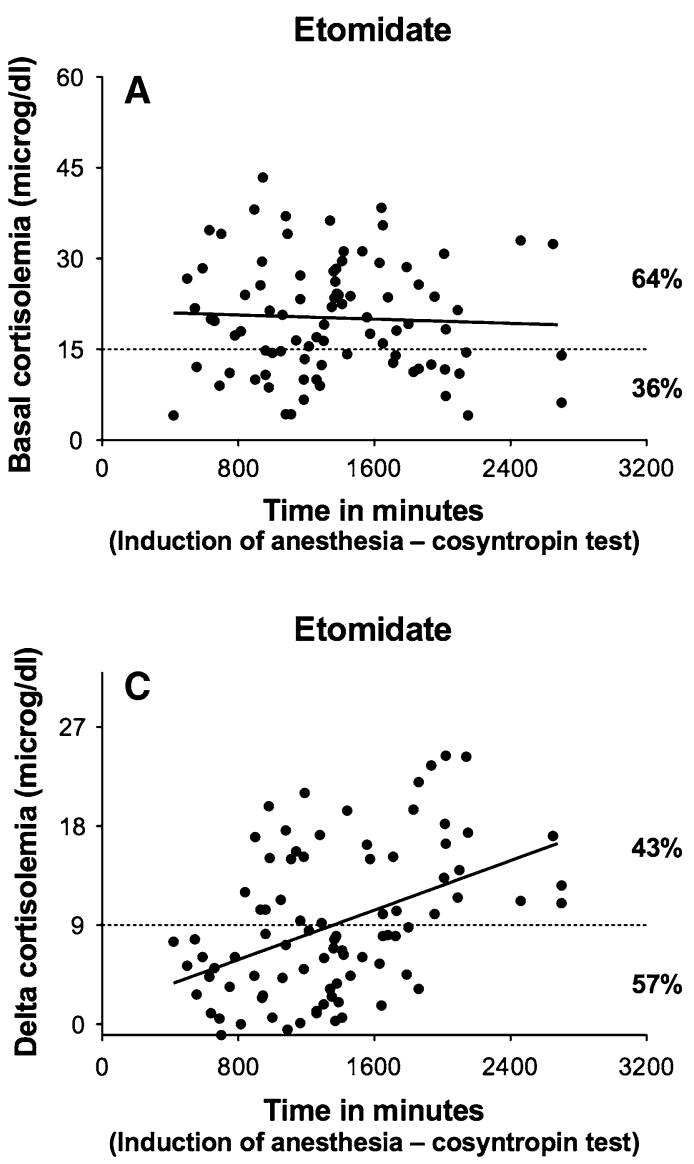

Fig. 1 Correlations between delta cortisolemia and time from induction of anaesthesia to cosyntropin test in patients who received etomidate (a, c, filled circles) and who did not receive etomidate (b, d open circles). Horizontal dotted line $(9 \mu \mathrm{d} / \mathrm{dL}$ for

Outcomes of etomidate-exposed patients

The duration of MV was 11 (6-19) days in the nonetomidate group and 13 (7-22) days in the etomidate group $(p=0.275)$, and the ICU length of stay c CIRCI definition from Consensus Task Force of Consensus statements from an international task force by the American College of Critical Care Medicine
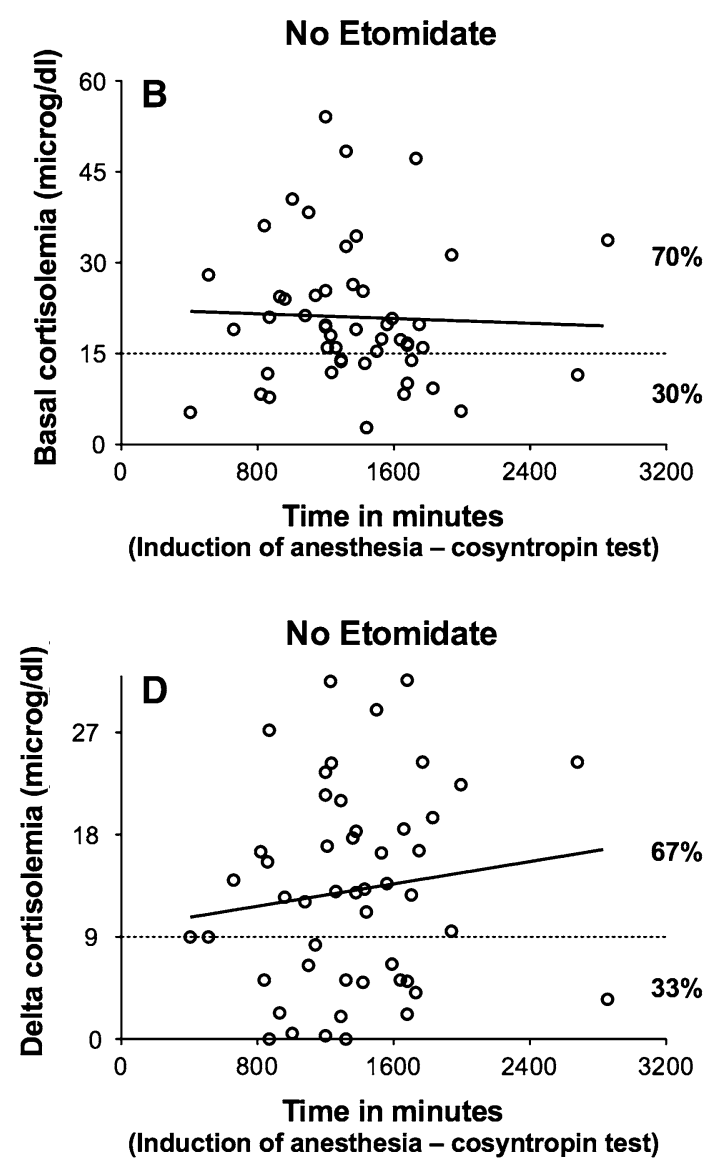

delta maximum and $15 \mathrm{mg} / \mathrm{dL}$ for baseline) discriminate between adapted corticosteroid function (upper) and corticosteroid insufficiency (lower). Percentages of patients by quadrant are provided

was 15 (9-28) days in the non-etomidate group and $16(11-27)$ days in the etomidate group $(p=0.422)$. Four $(7.4 \%)$ patients in the non-etomidate group and six $(6 \%)$ patients in the etomidate group died $(p=1)$. 
Table 3 Univariate analysis of factors relating to 28-day hospital-acquired pneumonia

\begin{tabular}{|c|c|c|c|}
\hline \multirow[t]{2}{*}{ Variables } & \multicolumn{2}{|c|}{ Hospital-acquired pneumonia } & \multirow[t]{2}{*}{$p$ value } \\
\hline & Yes $(N=65)$ & No $(N=84)$ & \\
\hline Etomidate & $49(75.4)$ & $46(54.8)$ & 0.012 \\
\hline Age (year) & $28(20-49)$ & $32(23-51)$ & 0.348 \\
\hline Sex (female) & $13(20)$ & $19(22.6)$ & 0.759 \\
\hline \multicolumn{4}{|l|}{ Medical history } \\
\hline Chronic pulmonary disease & $3(4.6)$ & $2(2.4)$ & 0.408 \\
\hline Cardiac insufficiency & $2(3)$ & $3(3.6)$ & 0.816 \\
\hline Diabetes mellitus & $1(1.5)$ & $4(4.8)$ & 0.328 \\
\hline Obesity & $7(10.8)$ & $14(16.7)$ & 0.485 \\
\hline Smoking & 0 & $5(6)$ & 0.979 \\
\hline Injury severity score & $30(24-41)$ & $29(22-34)$ & 0.090 \\
\hline Traumatic brain injury & 46 & 38 & 0.002 \\
\hline AIS thorax & $3(1-3)$ & $3(2-3)$ & 0.942 \\
\hline Aspiration pneumonia & $1(1.5)$ & $3(3.6)$ & 0.460 \\
\hline \multicolumn{4}{|l|}{ Fluid infusion prior to inclusion } \\
\hline Crystalloid fluid infusion (L) & $3(2-3.5)$ & $3(2-4)$ & 0.922 \\
\hline Colloid fluid infusion (L) & $1.8(1-3)$ & $1.5(1-2.5)$ & 0.573 \\
\hline Red cell units & $4(0-9)$ & $4(0.5-9)$ & 0.530 \\
\hline Plasma units & $3(0-7)$ & $3(0-6)$ & 0.537 \\
\hline Norepinephrine prior to inclusion ( $\mu \mathrm{g} / \mathrm{kg} / \mathrm{min})$ & $0.3(0.2-0.5)$ & $0.3(0.1-0.5)$ & 0.501 \\
\hline Duration of initial surgical procedure (hour) & $2(1-5)$ & $2(1-5)$ & 0.923 \\
\hline \multicolumn{4}{|l|}{ Duration from $(\mathrm{min})$} \\
\hline Trauma to tracheal intubation & $45(25-120)$ & $70(35-180)$ & 0.025 \\
\hline Trauma to hydrocortisone infusion & $1,440(1,200-1,935)$ & $1,440(1,110-1,800)$ & 0.571 \\
\hline Tracheal intubation to corticotropin test & $1,310(1,080-1,690)$ & $1,230(900-1,600)$ & 0.270 \\
\hline Tracheal intubation to hydrocortisone infusion & $1,370(1,140-1,750)$ & $1,290(960-1,660)$ & 0.270 \\
\hline \multicolumn{4}{|l|}{ Corticotropin test $(\mu \mathrm{g} / \mathrm{dL})$} \\
\hline Basal cortisolemia & $19.7(11.8-31.2)$ & $19.0(13.9-25.0)$ & 0.317 \\
\hline Delta $30 \mathrm{~min}$ & $6.4(2.0-12.4)$ & $5.6(2.6-11.4)$ & 0.742 \\
\hline Delta $60 \mathrm{~min}$ & $9.1(2.5-17.4)$ & $8.4(5.0-15.0)$ & 0.830 \\
\hline Antibioprophylaxis & $57(87.7)$ & $71(84.5)$ & 0.563 \\
\hline Oropharyngeal decontamination & $39(60)$ & $52(61.9)$ & 0.729 \\
\hline Stomach ulcer prevention & $46(70.7)$ & $53(63)$ & 0.532 \\
\hline Semi recumbent position $>30^{\circ}$ & $57(87.7)$ & $72(85.7)$ & 0.686 \\
\hline Protocol for glycaemia control & $61(93.8)$ & $78(92.6)$ & 0.727 \\
\hline
\end{tabular}

Results are expressed as the median with the interquartile range (IQR) in parenthesis, or as the number $(N)$ with the percentage in parenthesis, where appropriate

Table 4 Results of the logistic regression analysis for predictors of hospital-acquired pneumonia

\begin{tabular}{lcc}
\hline Predictors of HAP & Odds ratio $(95 \% \mathrm{CI})^{\mathrm{a}}$ & $p$ value \\
\hline Etomidate & $2.48(1.19 ; 5.18)$ & 0.016 \\
Traumatic Brain injury & $3.05(1.50 ; 6.21)$ & 0.002 \\
\hline & Adjusted odds & $p$ value \\
& ratio $(95 \% \mathrm{CI})^{\mathrm{b}}$ & \\
\hline Etomidate & $2.52(1.08 ; 5.87)$ & 0.032 \\
Traumatic Brain injury & $2.62(1.12 ; 6.13)$ & 0.026 \\
\hline
\end{tabular}

HAP Hospital-acquired pneumonia

${ }^{a}$ The model was adjusted for the study drug administration (hydrocortisone). Area under the curve (AUC) for the logistic regression model was 0.71 (Hosmer-Lemeshow's $p$ value: 0.94)

$\mathrm{b}$ The model was adjusted on the study drug and on the propensity score (AUC: 0.69)
Hydrocortisone improved the outcomes of etomidate-exposed patients

Etomidate increased the rates of both CIRCI and HAP. We therefore assessed the impact of hydrocortisone in the group of patients receiving etomidate. Of the 95 patients in the etomidate group, $45(52.6 \%)$ were treated with hydrocortisone and $50(47.4 \%)$ with placebo. Of the 45 patients receiving hydrocortisone in the etomidate group, $18(40 \%)$ developed HAP compared with $31(62 \%)$ of the 50 patients receiving placebo $(p=0.032$; Table 5). Of the 20 patients in the etomidate group with early hydrocortisone infusion ( $\leq 20 \mathrm{~h}$ after trauma), eight (40\%) developed HAP by day 28 compared with ten of the $25(40 \%)$ patients in the etomidate group with late hydrocortisone infusion ( $>20 \mathrm{~h}$ after trauma; $p=1)$. 
The duration of MV was 9 (6-16) days in patients receiving hydrocortisone and 18 (10-25) days in those receiving placebo $(p<0.001)$, and the ICU length of stay was 13 (8-20) days with hydrocortisone and 21 (14-28) days with placebo $(p<0.001)$ (Table 5). Three of 45 $(6.7 \%)$ patients in the hydrocortisone group and three of $50(6 \%)$ in the placebo group died $(p=1)$ (Table 5).

In the HYPOLYTE study [17], after the results of the corticotropin test were known, patients with CIRCI were treated for 7 days, whereas treatment was stopped in patients without CIRCI (see ESM Fig. S1). For the 79 patients with CIRCI in the etomidate group, 14 (38.9 \%) of 36 patients receiving hydrocortisone and $25(58.1 \%)$ of 43 patients receiving placebo developed $\operatorname{HAP}(p=0.088$; see ESM Table S2). The duration of MV as well as ICU length of stay were reduced in patients receiving hydrocortisone compared with placebo $(p<0.001$ for both durations; see ESM Table S2). In the etomidate group, 16 patients ( 9 patients in the hydrocortisone group and 7 in the placebo group) did not have CIRCI and were treated for 34 (20-49) h. Hydrocortisone did not alter the outcomes of patients without CIRCI in the etomidate group (see ESM Table S1).

\section{Discussion}

In this sub-study of the HYPOLYTE trial, basal cortisolemia was not modified by etomidate treatment, whereas the delta of cortisolemia was altered. Etomidate was found to be an independent risk factor for HAP in intubated trauma patients, and hydrocortisone was found to significantly decrease the rate of HAP and the duration of MV for etomidate-exposed patients. These results could have major implications in the care of severe trauma patients.
CIRCI corresponds to an inadequacy between the severity of illness and the cortisolemia [21]. CIRCI is defined by either an insufficient rise in cortisol production [22] and/or a peripheral resistance to glucocorticoids [23]. The combination of a basal cortisolemia of $<10 \mu \mathrm{g} / \mathrm{dL}$ and/or a delta cortisolemia of $<9 \mu \mathrm{g} / \mathrm{dL}$ provides the best specificity and sensitivity for the diagnosis of CIRCI in severe septic patients [24]. Recent recommendations of the American College of Critical Care Medicine have advocated the use of either basal or delta cortisolemia for the diagnosis of CIRCI in critically ill adult patients [25]. However, etomidate inhibits 11 beta-hydroxylase [4], inducing an iatrogenic corticosteroid insufficiency [26] that may be differentiated from CIRCI. Thus, the diagnosis of CIRCI after etomidate use is challenging and still poorly documented. As previously mentioned in a substudy of the CORTICUS trial [9], etomidate was able to bias the result of the cosyntropin test up to $36 \mathrm{~h}$ but did not alter basal cortisolemia. These results have already been described in the first $6 \mathrm{~h}$ after rapid sequence intubation with etomidate in trauma patients [18]. The current results confirm that after etomidate use, basal cortisolemia remains a reliable criterion for the diagnosis of CIRCI.

The controversy regarding the use of a single bolus of etomidate in critically ill patients was raised in the last decade, mainly in septic patients [3]. Etomidate increases both the rate of corticosteroid insufficiency and the rate of death in septic patients [8], but to date no causal link has been demonstrated. Etomidate is widely used in trauma patients as a single bolus for tracheal intubation. There are many advantages to using etomidate in this population, including a short duration of action with few cardiovascular side effects [2]. Despite these attractive characteristics, we observed an increased rate of HAP in etomidate-exposed patients. Moreover, Hildreth et al. [18] reported increases in the duration of MV and the ICU length of stay of trauma patients after etomidate use.

Table 5 Impact of hydrocortisone on outcomes of patients treated with etomidate

\begin{tabular}{|c|c|c|c|c|c|c|}
\hline \multirow{2}{*}{$\begin{array}{l}\text { Entire population } \\
\text { Hospital-acquired pneumonia, } \\
\quad N(\%) \text { : }\end{array}$} & \multicolumn{3}{|c|}{ Hydrocortisone $(N=73)$} & \multicolumn{3}{|c|}{ Placebo $(N=76)$} \\
\hline & $\begin{array}{l}\text { Etomidate } \\
\qquad(N=45)\end{array}$ & $\begin{array}{l}\text { No etomidate } \\
\quad(N=28)\end{array}$ & $p$ value & $\begin{array}{l}\text { Etomidate } \\
\qquad(N=50)\end{array}$ & $\begin{array}{l}\text { No etomidate } \\
\quad(N=26)\end{array}$ & $p$ value \\
\hline CIRCI $(N=113)$ & $14(39)$ & $6(30)$ & 0.506 & $25(58)$ & $6(43)$ & 0.319 \\
\hline No CIRCI $(N=36)$ : & $4(44)$ & $2(25)$ & 0.620 & $6(86)$ & $2(17)$ & 0.006 \\
\hline \multicolumn{3}{|l|}{ Etomidate population $(N=95)$} & \multicolumn{2}{|c|}{ Hydrocortisone $(N=45)$} & Placebo $(N=50)$ & $p$ value \\
\hline \multicolumn{3}{|c|}{ Hospital-acquired pneumonia, $N(\%)$} & \multicolumn{2}{|c|}{$18(40)$} & $31(62)$ & 0.032 \\
\hline ARDS or ALI, $N(\%)$ & & & & & $8(16)$ & 0.1 \\
\hline \multicolumn{7}{|l|}{ Vasoactive drugs } \\
\hline \multicolumn{3}{|c|}{ Norepinephrine, days, median (IQR) } & \multicolumn{2}{|c|}{$3(1-4)$} & $3(1-5)$ & 0.459 \\
\hline \multicolumn{3}{|c|}{ Delta in the 24 first hours, $\mu \mathrm{g} / \mathrm{kg} / \mathrm{min}$, median (IQR) } & \multicolumn{2}{|c|}{$-0.1(-0.25 ; 0)$} & $-0.01(-0.2 ; 0)$ & 0.299 \\
\hline \multicolumn{3}{|c|}{ Mechanical ventilation in ICU, days, median (IQR) } & \multicolumn{2}{|c|}{$9(6-16)$} & $18(10-25)$ & $<0.001$ \\
\hline \multicolumn{3}{|c|}{ Hospitalization in ICU, days, median (IQR) } & \multicolumn{2}{|c|}{$13(8-20)$} & $21(14-28)$ & $<0.001$ \\
\hline \multicolumn{2}{|l|}{ Death at day $28, N(\%)$} & \multicolumn{3}{|c|}{$3(6.7)$} & $3(6)$ & 1 \\
\hline
\end{tabular}

$A L I$ Acute lung injury, $A R D S$ acute respiratory distress syndrome, $C I R C I$ critical illness related corticosteroid insufficiency, ICU intensive care unit 
These data confirm the morbidity of etomidate previously demonstrated in septic patients.

The equilibrium of the inflammatory response is a major determinant in avoiding post-traumatic infections [27]. Etomidate increases pro-inflammatory cytokine production ex vivo in whole blood cell cultures challenged with lipopolysaccharide [28] and could therefore prolong the systemic inflammatory response syndrome (SIRS) frequently observed in trauma patients. Prolonged SIRS is predictive of nosocomial infection in trauma patients [29] and has also been correlated with corticosteroid dysfunction in critically ill [30] and trauma patients [13]. It may therefore be hypothesized that etomidate exposes patients to HAP, at least in part, through an excessive inflammatory response.

Published data suggest that adequate cortisol production is critical for normal host defence against infection [15]. In this setting, patients presenting with Addison disease are more susceptible to infections [31]. Cortisol, a natural hormone, increases neutrophil activity [32, 33], preserves monocyte function and increases the homing of dendritic cells [34]. With respect to glucocorticoid therapy, high-dose methylprednisolone and low-dose hydrocortisone display different effects on the immune response [35], and while the former's regimen is immunosuppressive and induces apoptosis of numerous immune cells [36, 37], hydrocortisone acts as an immunomodulatory drug [34]. In comparison to those receiving placebo, low doses of hydrocortisone were found to enhance neutrophil functions [32] and decrease the overwhelming inflammatory response in septic patients [38]. At the same time, interleukin-12 production was increased, whereas interleukin-10 decreased-with no modification of monocytic human leukocyte antigen DR expression. These data suggest that in septic patients, a low-dose of hydrocortisone may enhance the immune response rather than induce "immunosuppression" [38]. In intubated patients with respiratory failure and CIRCI, hydrocortisone was found to accelerate weaning from ventilatory support [39]. It was also demonstrated that hydrocortisone reduced both the mortality rate and the duration of hospitalization in a population of patients suffering from severe community-acquired pneumonia [40]. Thus, low doses of hydrocortisone should systematically be considered after a single bolus of etomidate in patients at high risk for CIRCI and HAP. In a recent study, Payen et al. [10] failed to demonstrate any improvement in outcomes when treating etomidateexposed patients with hydrocortisone. The discrepancies between our results and these data merit explanation. Firstly, Payen et al. included a general population of ICU patients, whereas we studied trauma patients and treated all etomidate-exposed patients, although only patients with CIRCI were treated 7 days in the HYPOLYTE study. Secondly, the rate of HAP was not studied. Finally, there was an important trend in favour of hydrocortisone regarding ICU length of stay and ventilator days [4 (IQR $1-10)$ vs. 8 (IQR 4-17) days and 2 (IQR 1-10) versus 4 (IQR 1-10) days, respectively]. One could hypothesize that the Payen et al. study [10] lacked power for these two outcomes.

This study displays a number of strengths, mainly because the data are from a multi-centre, double-blind study and also because this is the first study that reports the impact of etomidate use in a specific population of trauma patients. However, limitations must be noted. First, the reasons for etomidate use were neither documented nor controlled, although no imbalance in etomidate use was apparent between the centres (data not shown). Also, one could hypothesize that etomidate was used in sicker patients. However, the severity scores did not appear to be different between patients with or without etomidate, and etomidate was associated with HAP in a multivariate analysis. However, the use of other trauma severity scores [41] or of generalist severity scores [42] with better prognostic values may have provided other information. Second, we used a more liberal CIRCI definition than the consensus statement, which was not available at the beginning of the study in 2006 (basal cortisolemia $<10$ vs. $15 \mu \mathrm{g} / \mathrm{dL}$ ) [25]. Previous studies in trauma patients used a basal cortisolemia threshold of $\geq 15 \mu \mathrm{g} / \mathrm{dL}$ [12-14], and we chose a definition proposed by Annane et al. [43]. Of the 149 patients, 23 (15\%) would not have had CIRCI if the current definition of the consensus statement had been used [25]. Third, the effect of etomidate on adrenal function is transient, but we report more pneumonia (early and late onset) in the etomidate group. No definitive conclusion can be drawn from this descriptive study in terms of the physiological mechanism that links etomidate to pneumonia. In the HYPOLYTE study, the majority of pneumonia was early onset pneumonia [ $<$ day 8,54 early pneumonia $(83 \%)]$. This may explain, at least in part, this surprising result. Finally, etomidate-induced corticosteroid insufficiency (characterized by a decrease in delta cortisolemia with no alteration of basal cortisolemia) is an independent risk factor for HAP, which strengthens the concept of CIRCI based on hyporeactivity to corticotropin [21].

\section{Conclusions}

A single bolus of etomidate is an independent risk factor for HAP in intubated trauma patients. A low-dose of hydrocortisone prevented etomidate-induced susceptibility to HAP. Even after etomidate injection, basal cortisolemia remains a reliable criterion for the diagnosis of CIRCI. These data should alert physicians to limit the use of etomidate for the intubation of severe trauma patients unless they use hydrocortisone to counteract the deleterious effects of the drug. 
Acknowledgments HYPOLYTE investigators: Service de réanimation, $\mathrm{CHU}$ de Bordeaux: Jean Francois Cochard, MD; Vincent Cottenceau, MD; Philippe Dabadie, MD; Alain Leger, MD; Francoise Masson, MD; Laurent Merson, MD; Laurent Petit, MD; Catherine Pinaquy MD; Service de réanimation, $\mathrm{CHU}$ de Brest: Charles Arvieux, MD; Jean Philippe Aubouin, MD; Francois Bernage, MD; Guy Cochard, MD; Edith Etienne, MD; Herve Floch, MD; Emilie Guillard, MD, Francois Lion, MD; Yves Ozier, MD; Philippe Reynaud, MD; Anne de Tinteniac, MD; Jean Paul Wargnier, MD; Service d'Anesthesie Reanimation chirurgicale, CHU de Nantes: Jean Francois Arnould, MD; Karim Asehnoune, MD; Dominique Demeure dit Latte, MD; Philippe Champin, MD; Nolwenn Chatel Josse, MD; Anne Marie Chupin, MD; Olivier Courtin, MD; Romain Dumont, MD; Olivier Loutrel, MD; Pierre Joachim Mahe, MD; Edouard Naux, MD; Ronan Le Floch, MD; Jean Yves Lepage, MD; Pascale Nauleau, MD; Michel Pinaud, $\mathrm{MD}$; Antoine Roquilly (MD); Service de réanimation $\mathrm{CHU}$ de Rennes: David Aguillon, MD; Jean Paul Bleichner, MD; Charles
Chavanaz, MD; Axelle Maurice, MD; Michele Tanguy (MD); Service de reanimation polyvalente $\mathrm{CHU}$ de Nantes: Cédric Bretonniere, MD; No Etomidatel Brule, MD; Laurence Gabillet, MD; Laurent Nicollet, MD; Daniel Villers, MD; Olivier Zambon (MD); Service de reanimation polyvalente, CHD la Roche sur Yon: Guillaume Belliard, MD; Frederic Bontemps, MD; Eva Clementi, MD; Maud Fiancette, MD; Laurent Martin Lefevre, MD; Jean Reignier, MD; Isabelle Vinatier (MD); Service de reanimation CHU de Tours: Martine Ferrandière, MD; Jacques Fusciardi, MD; Francois Lagarrigue (MD). The Nantes University Hospital was the study sponsor. The French Ministry of Health provided financial support (2006 Clinical Research Hospital Programme PHRC 2006, inter-région Ouest). The laboratory SERB provided hydrocortisone.

\section{Conflicts of interest None.}

\section{References}

1. Forman SA (2011) Clinical and molecular pharmacology of etomidate. Anesthesiology 114:695-707

2. Reynolds SF, Heffner J (2005) Airway management of the critically ill patient: rapid-sequence intubation. Chest 127:1397-1412

3. Annane D (2005) ICU physicians should abandon the use of etomidate! Intensive Care Med 31:325-326

4. Vinclair M, Broux C, Faure P, Brun J, Genty C, Jacquot C, Chabre O, Payen J-F (2007) Duration of adrenal inhibition following a single dose of etomidate in critically ill patients. Intensive Care Med 34:714-719

5. Malerba G, Romano-Girard F, Cravoisy AL, Dousset B, Nace L, Lvy B, Bollaert P-E (2005) Risk factors of relative adrenocortical deficiency in intensive care patients needing mechanical ventilation. Intensive Care Med 31:388-392

6. Lipiner-Friedman D, Sprung CL, Laterre PF, Weiss Y, Goodman SV, Vogeser M, Briegel J, Keh D, Singer M, Moreno R, Bellissant E, Annane D, Corticus Study Group (2007) Adrenal function in sepsis: the retrospective Corticus cohort study. Crit Care Med 35:1012-1018

7. Jabre P, Combes X, Lapostolle F, Dhaouadi M, Ricard-Hibon A, Vivien B, Bertrand L, Beltramini A, Gamand P, Albizzati S, Perdrizet D, Lebail G, Chollet-Xemard C, Maxime V, BrunBuisson C, Lefrant JY, Bollaert PE, Megarbane B, Ricard JD, Anguel N, Vicaut E, Adnet F, KETASED Collaborative Study Group (2009) Etomidate versus ketamine for rapid sequence intubation in acutely ill patients: a multicentre randomised controlled trial. Lancet 374:293-300
8. Albert SG, Ariyan S, Rather A (2011) The effect of etomidate on adrenal function in critical illness: a systematic review. Intensive Care Med 37:901-910

9. Cuthbertson BH, Sprung CL, Annane D, Chevret S, Garfield M, Goodman S, Laterre PF, Vincent JL, Freivogel K, Reinhart K, Singer M, Payen D, Weiss YG (2009) The effects of etomidate on adrenal responsiveness and mortality in patients with septic shock. Intensive Care Med 35:1868-1876

10. Payen JF, Dupuis C, Trouve-Buisson T, Vinclair M, Broux C, Bouzat P, Genty C, Monneret D, Faure P, Chabre O, Bosson JL (2012) Corticosteroid after etomidate in critically ill patients: a randomized controlled trial. Crit Care Med 40:29-35

11. Cook DJ, Walter SD, Cook RJ, Griffith LE, Guyatt GH, Leasa D, Jaeschke RZ, Brun-Buisson C (1998) Incidence of and risk factors for ventilator-associated pneumonia in critically ill patients. Ann Intern Med 129:433-440

12. Hoen S, Asehnoune K, Brailly-Tabard S, Mazoit J-X, Benhamou D, Moine P, Edouard AR (2002) Cortisol response to corticotropin stimulation in trauma patients: influence of hemorrhagic shock. Anesthesiology 97:807-813

13. Hoen S, Mazoit J-X, Asehnoune K, Brailly-Tabard S, Benhamou D, Moine P, Edouard AR (2005) Hydrocortisone increases the sensitivity to alpha1adrenoceptor stimulation in humans following hemorrhagic shock. Crit Care Med 33:2737-2743
14. Cohan P, Wang C, McArthur DL, Cook SW, Dusick JR, Armin B, Swerdloff R, Vespa P, Muizelaar JP, Cryer HG, Christenson PD, Kelly DF (2005) Acute secondary adrenal insufficiency after traumatic brain injury: a prospective study. Crit Care Med 33:2358-2366

15. Burchard K (2001) A review of the adrenal cortex and severe inflammation: quest of the "eucorticoid" state. J Trauma 51:800-814

16. Offner PJ, Moore EE, Ciesla D (2002) The adrenal response after severe trauma. Am J Surg 184:649-653

17. Roquilly A, Mahe PJ, Seguin P, Guitton $\mathrm{C}$, Floch H, Tellier AC, Merson L, Renard B, Malledant Y, Flet L, Sebille V, Volteau C, Masson D, Nguyen JM, Lejus C, Asehnoune K (2011) Hydrocortisone therapy for patients with multiple trauma: the randomized controlled HYPOLYTE study. JAMA 305:1201-1209

18. Hildreth AN, Mejia VA, Maxwell RA, Smith PW, Dart BW, Barker DE (2008) Adrenal suppression following a single dose of etomidate for rapid sequence induction: a prospective randomized study. J Trauma 65:573-579

19. American Thoracic Society, Infectious Diseases Society of America (2005) Guidelines for the management of adults with hospital-acquired, ventilator-associated, and healthcareassociated pneumonia. Am J Respir Crit Care Med 171:388-416

20. Lepelletier D, Roquilly A, Demeure dit latte D, Mahe PJ, Loutrel O, Champin P, Corvec S, Naux E, Naux E, Pinaud M, Lejus C, Asehnoune K (2010) Retrospective analysis of the risk factors and pathogens associated with earlyonset ventilator-associated pneumonia in surgical-ICU head-trauma patients. J Neurosurg Anesthesiol 22:32-37 
21. Marik PE (2009) Critical illness-related corticosteroid insufficiency. Chest 135:181-193

22. Bornstein SR (2009) Predisposing factors for adrenal insufficiency. N Engl J Med 360:2328-2339

23. Meduri GU, Muthiah MP, Carratu P, Eltorky M, Chrousos GP (2005) Nuclear factor-kappaB- and glucocorticoid receptor alpha-mediated mechanisms in the regulation of systemic and pulmonary inflammation during sepsis and acute respiratory distress syndrome. Evidence for inflammation-induced target tissue resistance to glucocorticoids. NeuroImmunoModulation 12:321-338

24. Annane D, Maxime V, Ibrahim F, Alvarez JC, Abe E, Boudou P (2006) Diagnosis of Adrenal Insufficiency in Severe Sepsis and Septic Shock. Am J Respir Crit Care Med 174:1319-1326

25. Marik PE, Pastores SM, Annane D, Meduri GU, Sprung CL, Arlt W, Keh D, Briegel J, Beishuizen A,

Dimopoulou I, Tsagarakis S, Singer M, Chrousos GP, Zaloga G, Bokhari F, Vogeser M, American College of Critical Care Medicine (2008) Recommendations for the diagnosis and management of corticosteroid insufficiency in critically ill adult patients: Consensus statements from an international task force by the American College of Critical Care Medicine. Crit Care Med 36:1937-1949

26. Varga I, Rácz K, Kiss R, Fütö L, Tóth M, Sergev O, Gláz E (1993) Direct inhibitory effect of etomidate on corticosteroid secretion in human pathologic adrenocortical cells. Steroids 58:64-68

27. Moore FA, Sauaia A, Moore EE, Haenel JB, Burch JM, Lezotte DC (1996) Postinjury multiple organ failure: a bimodal phenomenon. J Trauma 40:501-510
28. Larsen B, Hoff G, Wilhelm W, Buchinger H, Wanner GA, Bauer M (1998) Effect of intravenous anesthetics on spontaneous and endotoxinstimulated cytokine response in cultured human whole blood. Anesthesiology 89:1218-1227

29. Bochicchio GV, Napolitano LM, Joshi M, Knorr K, Tracy JK, Ilahi O, Scalea TM (2002) Persistent systemic inflammatory response syndrome is predictive of nosocomial infection in trauma. J Trauma 53:245-250

30. Kwon YS, Suh GY, Jeon K, Park SY, Lim SY, Koh W-J, Chung MP, Kim H, Kwon OJ (2010) Serum cytokines and critical illness-related corticosteroid insufficiency. Intensive Care Med 36:1845-1851

31. Beisel WR, Rapoport MI (1969) Interrelations between adrenocortical functions and infectious illness. N Engl J Med 280:596-604

32. Kaufmann I, Briegel J, Schliephake F, Hoelzl A, Chouker A, Hummel T, Schelling G, Thiel M (2008) Stress doses of hydrocortisone in septic shock: beneficial effects on opsonizationdependent neutrophil functions. Intensive Care Med 34:344-349

33. Heller AR, Heller SC, Borkenstein A, Stehr SN, Koch T (2003) Modulation of host defense by hydrocortisone in stress doses during endotoxemia. Intensive Care Med 29:1456-1463

34. Webster JI, Tonelli L, Sternberg EM (2002) Neuroendocrine regulation of immunity. Annu Rev Immunol 20:125-163

35. Visser J, van Boxel-Dezaire A, Methorst D, Brunt T, De Kloet ER, Nagelkerken L (1998) Differential regulation of interleukin-10 (IL-10) and IL- 12 by glucocorticoids in vitro. Blood 91:4255-4264

36. Rhen T, Cidlowski JA (2005)

Antiinflammatory action of glucocorticoids-new mechanisms for old drugs. N Engl J Med 353:1711-1723
37. Lepelletier Y, Zollinger R, Ghirelli C, Raynaud F, Hadj-Slimane R, Cappuccio A, Hermine O, Liu Y-J, Soumelis V (2010) Toll-like receptor control of glucocorticoid-induced apoptosis in human plasmacytoid predendritic cells (pDCs). Blood 116:3389-3397

38. Keh D, Boehnke T, Weber-Cartens S, Schulz C, Ahlers O, Bercker S, Volk H-D, Doecke W-D, Falke KJ, Gerlach $\mathrm{H}$ (2003) Immunologic and hemodynamic effects of "low-dose" hydrocortisone in septic shock: a double-blind, randomized, placebocontrolled, crossover study. Am J Respir Crit Care Med 167:512-520

39. Huang C-J (2006) Association between adrenal insufficiency and ventilator weaning. Am J Respir Crit Care Med 173:276-280

40. Confalonieri M, Urbino R, Potena A, Piattella M, Parigi P, Puccio G, Della Porta R, Giorgio C, Blasi F, Umberger R, Meduri GU (2005) Hydrocortisone infusion for severe community-acquired pneumonia: a preliminary randomized study. Am J Respir Crit Care Med 171:242-248

41. Sartorius D, Le Manach Y, David JS, Rancurel E, Smail N, Thicoïpé M, Wiel E, Ricard-Hibon A, Berthier F, Gueugniaud PY, Riou B (2010) Mechanism, glasgow coma scale, age, and arterial pressure (MGAP): a new simple prehospital triage score to predict mortality in trauma patients. Crit Care Med 38:831-837

42. Minne L, Abu-Hanna A, de Jonge E (2008) Evaluation of SOFA-based models for predicting mortality in the ICU: a systematic review. Crit Care 12:R161

43. Annane D, Bellissant E, Cavaillon J-M (2005) Septic shock. Lancet 365:63-78 